\title{
Biodegradation of Textile Dye Reactive Black GDN by Free Cells Isolated from Soil and Textile Effluents
}

\author{
Palkesh D. Gandhi ${ }^{1}$ and Sumaiya A. Shaikh ${ }^{2 *}$ \\ ${ }^{1}$ Shree P.M Patel institute of PG studies and Research in Science, Affiliated by Sardar Patel \\ University, Anand, India \\ ${ }^{2}$ Department of Microbiology, C.B.Patel Computer College and J.N.M.Patel Science College, \\ Bharthana (Vesu), Surat -395017, India \\ *Corresponding author
}

\section{A B S T R A C T}

\section{Keywords}

Bacterial consortium, Biological treatment, Decolourization, Dyeing effluent, Reactive dye

Article Info

Accepted:

12 March 2021

Available Online:

10 April 2021
Azo dyes, which are characterized by azo bonds, are a predominant class of colorants used in tattooing, cosmetics and consumer products. As per the requirement for dyestuff, dyed clothing in the effluent is less susceptible to acids, bases, and oxygen. Thus, conventional chemical and physical methods are not efficient in degrading the dyes. Some microorganisms have the capability to utilize the dyes as an energy source. These dyes are metabolized by bacteria to colourless aromatic amines or non-toxic compound bye enzymatic activity. Wastewater from textile industries poses a high environmental impact and their needs to be treated before discharged into the environment. The present study deals with the degradation of Reactive black GDN by different bacterial cultures isolated from a contaminated site. Amongst 5 cultures, the isolate 4 displayed $96 \%$ decolourisation of Reactive black GDN $\left(100 \mathrm{mgl}^{-1}\right)$ in $24 \mathrm{~h}$ to $72 \mathrm{~h}$. The colour removal efficiency of the isolate was further improved by optimizing various parameters. The decolourisation of the dye was 1.9 times higher under static as compared to shaking condition. The $\mathrm{pH} 7.0$ and $37^{\circ} \mathrm{C}$ temperature were found to be optimum for the decolourisation of the dye. The isolate was able to decolorize the dye in the range of $50-500 \mathrm{mg} \mathrm{l}^{-1}$.

\section{Introduction}

Usually synthetic dyes are more stable against biodegradation because of having complex aromatic molecular structures (Aksu, 2005) and textile, cosmetic, pharmaceutical, paper and food industries use synthetic dyes widely (Pandey et al., 2007). About 10,000 different dyes and pigments are used in textile industries and over 70-105 tons are produced worldwide per annum (Daneshvar et al., 2007). The production and utilization of dyestuff is increasing because of the rapid increase of 
industrialization and man's urge for colour (Mohan et al., 2002). Because of their huge assortment of dye shades, high wet fastness profiles, ease of application, brilliant dyes and minimal energy consumption, reactive dyes are widely used in the textile industries (Shah et al., 2013). There are three common groups of reactive dyes: Azo, pthalocyanine and anthraquinone (Axelsson et al., 2006), most of which are harmful, carcinogenic and mutagenic (Acuner and Dilek, 2004; Rauf and Stiborova et al., 2013). Irregular discharge of highly toxic and coloured effluent containing reactive dyes causes damage to the aquatic environment. Because of the presence of heavy metals, chlorides, aromatics, reactive dyes might be toxic to some aquatic life and may significantly affect photosynthetic activity in aquatic phototrophs because of reduced light penetration (Celia and Suruthi, 2016). Reactive azo dyes have high tinctorial value and less than $1 \mathrm{ppm}$ of the dye produces obvious coloration (Gupta et al., 2003). For the removal of dyes, colour and harmful compounds from wastewater, various physical and chemical methods such as adsorption, coagulation-flocculation, oxidation and electrochemical methods can be used (Lin and Peng, 1994).But these methods have many drawbacks like highsludge production, high-energy costs, and formation of by-products (Sarioglu et al., 2007). Conversely, being low cost and environmentally benign, bioprocessing can overcome these demerits (Kurade et al., 2017).

India has emerged as one of the largest garment-manufacturing country in the world. The garment sector has become the largest sector of the country's foreign exchange earnings and employs about 50\% of its industrial work force (Farhana et al., 2015).The textile industries use large amount of reactive dyes in their production processes and discharge waste water into sewers and drains without any treatment (Chindah et al., 2004). The physicochemical parameters of the effluents in India are much higher than the standard value recommended by Department of Environment (Shuchismita and Ashraful, 2015). The presence of reactive dyes in surface and subsurface water is making them not only aesthetically objectionable but also harmful for animals and causing many human health hazards resulting in diseases, viz. perforation of nasal septum, mucous membrane, dermatitis, and severe irritation of respiratory tract and toxicological effects as well as allergenic potential (Rovira and Domingo, 2019). Untreated textile effluents are spreading in the river, lake and other water body and impart a chemical concentration to the climate; its integrity renders the environmental quality fairly deplorable affecting plant growth and aquatic biodiversity. Because of this, people living around textile industries are now being threatened due to the environmental degradation (Sultana et al., 2009). Therefore, a sustainable bioprocess is badly required to remedy the harmfulness imparted by the reactive dyes in the untreated textile effluents.

In the recent years, a number of studies have focused on using some wide variety of bacteria, fungi, yeast and algae (Mishra and Malik, 2014; Veena et al., 2019) for degrading and absorbing dyes from wastewater. A wide variety of bacteria, fungi, yeast and algae are able to decolorize and degrade a wide range of dyes (Ayed et al., 2010). Under optimum conditions, bacteria can rapidly degrade and even completely mineralize many reactive dyes (Chen et al., 2003). The intermediate metabolites such as aromatic amines, and toxic or non-toxic compounds generated 
during the decolourisation process, can be degraded by the hydroxylase and oxygenase produced by bacteria (Wanyonyi et al., 2017).

In such manner, achievement of the textile reactive dye-degrading bacteria from the indigenous environment is very important. Bacteria present in the polluted textile effluents might have capabilities to degrade textile reactive dyes. Although several studies have been done showing absorption and degradation of dyes by microorganisms (Shen et al., 2015) additional studies are needed to develop biotechnology to degrade and detoxify the reactive black GDN dyes in effluents and wastewaters generated from textile industries. In the present study reported herein, bacteria were isolated and identified from polluted textile effluents and the surrounding soils. These isolates decolorized reactive dyes used in the textile industries.

Different physicochemical parameters were optimized for decolourisation of reactive Black GDN, the reactive dye commonly used in textile industries, and bacterial biodegradation was shown as the mechanism of decolourisation of reactive Black GDN.

\section{Materials and Methods}

\section{Dyestuff, media and chemicals}

Stock solution of the reactive black GDNN was prepared by dissolving $1 \mathrm{~g}$ of dye into $1000 \mathrm{~mL}$ of sterile distilled water, filtered and stored in brown bottle at room temperature. From the stock, working solution was prepared to give a final concentration of $100 \mathrm{mg} \mathrm{L}^{-1}$ and used for isolation, enrichment and screening of the potent dye decolorizing bacteria. All reagents media and ingredients were of analytical grade with desired purity and purchased from HiMedia Laboratories, India; Merck and Germany.

\section{Isolation of organism}

The bacterial isolates were isolated by serial dilution method using streak plate technique on Nutrient broth ( $\mathrm{gL}^{-1}$ Peptone-5, Meat extract-1, Yeast extract-2, NaCl-5, pH-7) A stock solution of the dye $\left(1000 \mathrm{mg} \mathrm{L}^{-1}\right)$ was prepared in distilled water and used for all studies. The flasks were incubated at $37^{\circ} \mathrm{C}$ under shaking conditions (130rpm) and steady condition. After $48 \mathrm{~h}$ of incubation, $1.0 \mathrm{ml}$. of the culture broth was appropriately diluted and plated on Nutrient Agar (gL-1 Peptone-5, Meat extract-1, Yeast extract-2, NaCl-5, Agar-15, pH-7.0)

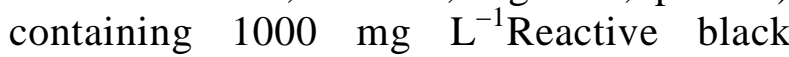
GDN.

The Morphologically distinct bacterial isolates showing clear zones around their colonies due to decolorization of dye were selected for further studies. The pure culture stocks of these isolates were stored at $4{ }^{\circ} \mathrm{C}$ on Nutrient Agar slants containing $100 \mathrm{mg}$ $\mathrm{L}^{-1}$ of Reactive black GDN. These isolates were screened for their ability to decolorize Reactive Black GDN in liquid culture.

\section{Growth and colony characteristics}

Growth and colony characteristics for all the 8 bacterial isolates were carried out by inoculating $1 \mathrm{ml}\left(1.5 \times 10^{9} \quad\right.$ approximate suspension/ml according to McFarland standard) culture into Nutrient broth medium and streak on nutrient agar plate.

Cultures were grown overnight in Nutrient broth medium and next day a $1 \mathrm{ml}$ young culture was transferred to nutrient agar plate with dye $(1000 \mathrm{mg} / \mathrm{lit})$ and slants. They were incubated at $37^{\circ} \mathrm{C}$ for 24 h. (Fig.3) 


\section{Gram reaction and cell morphology}

Gram's staining of the $24 \mathrm{~h}$ young cultures of all the isolates was performed to study Gram reaction and the cell morphology (Bartholomew J w., Mittwer t., 1952).(Fig.2)

\section{Biochemical tests}

All biochemical tests (Oxidase, Catalase, Indole, M-R, V-P, Citrate, Urease, Starch, $\mathrm{H}_{2} \mathrm{~S}$ Production, TSI, Gelatine, Glucose, Sucrose) were prepared in respective, test tubes, flasks, and petri dishes. Reagents required for different biochemical tests were prepared and stored at $4^{\circ} \mathrm{C}$ in refrigerator. Overnight grown cultures of all 8 isolates were inoculated $10 \mu 1$ in media and incubated at $37^{\circ} \mathrm{C}$ for $24 \mathrm{hrs}$.

Dye decolorizing isolates were preliminary identified on the basis of morphological, cultural and biochemical characteristics according to Bergey's Manual of Systematic Bacteriology (Staley et al., 2001).(Fig.4)

\section{Screening for decolourisation}

The bacterial isolates were analysed for the degradation of reactive black GDNN dye in broth cultures. The flask containing nutrient broth medium [Peptone 10.000 gram, Beef extract 10.000grm, Sodium chloride $5.000 \mathrm{grm}$, and $1000 \mathrm{ml}$ distilled water] and dye was inoculated using $1 \mathrm{ml}$ (1.5x $10^{9}$ approximate suspension $/ \mathrm{ml}$ according to McFarland standard)of isolated bacterial suspension. The culture flasks were incubated on an orbital shaker with $130 \mathrm{rpm}$, at $37^{\circ} \mathrm{C}$. and in steady condition in incubator at $37^{\circ} \mathrm{c}$. The flasks without inoculation were kept as control. OD values and growth of organism were measured spectrophotometrically at $530 \mathrm{~nm}$ to estimate the decolourisation process. The rate of decolourisation was calculated using the following formula.(Fig.1)
$\%$ Decolorization

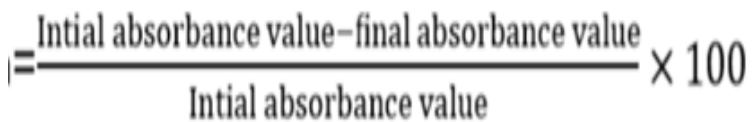

Various factors were optimized to achieve highest degradation by the selected bacterial isolate.

\section{Effect of pH}

The bacterial culture was inoculated in 100 $\mathrm{ml}$ nutrient broth medium with Reactive black GDN dye at various $\mathrm{pH}$. ranging from $4,6,8$. The flasks with different $\mathrm{pH}$ were kept in incubator for $24 \mathrm{hrs}$, 48hrs, and $72 \mathrm{hrs}$ at $37^{\circ} \mathrm{c}$. These flasks were drawn at every 24 hours intervals for dye decolourisation assay. Readings were taken after every 24 hours for 3 successive days.(Graph.5\&6)

\section{Effect of Incubation time}

The incubation time varying from $24 \mathrm{hrs}$ to $96 \mathrm{hrs}$ at $37^{\circ} \mathrm{c}$ were examined for the detection of optimum incubation time required for the degradation of dye by bacterial isolate. These flasks were drawn at 24 hours intervals for dye decolourisation assay. Readings were taken after every 24 hours to 96 hours.(Graph.7)

\section{Results and Discussion}

The sample were collected in sterilized container from Sachin GIDC, Surat and analysed Physico-chemical characterization. The colour, temperature and $\mathrm{pH}$ of the sample were recorded on the site and samples were transported to the laboratory by storage at $4^{\circ}$ C. Other physico-chemical characteristics like colour, $\mathrm{pH}$ and temperature were measured on the same day of collection of sample as per Table 1. The raw sewage was black in colour because of the types of dyes generally used. As the stages of treatment progressed, the 
colour of effluents changed from black- red and finally light brown. The black colour of the incoming effluent is due to wide use of black dye in dyeing and printing industries, thus, it contributes more to the effluent's colour compared to other dyes. The light brown colour of the finally released effluent after treatment may be due to the dirty water condition. The $\mathrm{pH}$ of the untreated effluent was 9.8, which reduced during treatment to near neutral 7.8.

\section{Isolation and screening of bacterial strains}

The selective enrichment of liquid effluent, sludge, and soil sample collected from the Sachin GIDC, Surat and waste disposal sites, led to the isolation of 8 morphologically different bacterial isolates. Gram strain of all isolates indicated the presence of 2 Gram positive and 6 Gram negative organisms (Table 3). The pure cultures were preserved on $\mathrm{N}$-agar medium at $4^{\circ} \mathrm{C}$. All 8 isolates were tested individually for their ability to decolorize Reactive black GDN separately at the concentration of $100 \mathrm{mg} \mathrm{L}^{-1}$ each (Table 2). All isolates decolorize the dyes with different capacity ranging from lowest $12 \%$ to highest $94 \%$ in case of Reactive Black GDN. Five potential isolates namely; ISO1, ISO3, ISO4, ISO5, and ISO6 showed good decolourisation efficiency in Reactive black GDN. The dye concentration in effluent from textile printing house is approximately in the range of 50 to $500 \mathrm{mg} \mathrm{L}^{-1}$. This value is typical of those used in studies on treatment for azo dye containing effluent. However, change in operating processes may lead to still high concentration of dye in effluent. Keeping in mind the above fact, we used $100 \mathrm{mg} \mathrm{L}^{-1}$ dye concentrations to check microbe's ability to decolorize different dyes. Decolourization of Reactive Black GDN was around $97 \%$ by ISO4, ISO5 and ISO6 at optimum pH. ISO1, ISO3, and ISO7 decolorized this dye at, $32 \%$, $40 \%$, and $75 \%$, respectively. The dye that has been mainly studied, Reactive Black GDN, was decolorized to more than $70 \%$ by all the isolates whereas this dye was decolorize up to $98 \%$ by ISO4 and ISO6, the most studied organism in this study. The lowest and highest decolourisation of different concentrations of dyes by selected organisms were in the range of $12 \%$ to $94 \%$ for Reactive Black GDN. The isolation of different microorganisms from the sample indicates the natural adaptation of microorganisms to survive in the presence of toxic dyes. The difference in their rate of decolourisation may be due to the loss of ecological interaction, which they might be sharing with each other under natural conditions.

\section{Growth and morphological characteristics}

Morphological characteristics was obtained for all the 8 bacterial isolates. Wide variation in morphological characteristics was found indicating diversified bacterial species in textile effluent. The Gram's staining indicated that out of 8 isolates, $\mathrm{Gm}+\mathrm{ve}$ rods-1, Gm -ve short rods -6 , and $\mathrm{Gm}+\mathrm{ve}$ cocci - 1, and (Fig.2). The additional information from Gram staining was in the form of cell morphology and arrangement. The growth pattern of these isolates on nutrient agar plate was filiform, echinulate and arborescent with moderate or large growth abundance (Table 4). It was found that most of the organisms were of rod shaped including short and big rods (Fig.2). The potential dye decolourizers were found in, $\mathrm{Gm}+\mathrm{ve}$ and $\mathrm{Gm}$-ve group. When organisms were grown on $\mathrm{N}$-agar plate, there was characteristic pigmentation of colonies like white, dirty white, grey, light yellow and light brown. One isolates ISO5 were found to produce dark pigmentation of yellow(Fig.3). Size of colonies varied from small to moderate to large having smooth or rough texture with even, uneven, wavy filamentous margins and circular, rhizoid and irregular forms. 
Table.1 Characteristics of samples collected from different stages of Sachin GIDC, Surat

\begin{tabular}{|c|c|c|c|c|}
\hline Sr. & Sample & Nature of Sample & Colour & pH \\
\hline $\mathbf{1}$ & Effluent 1 & Liquid & Dark black & 9.8 \\
\hline $\mathbf{2}$ & Effluent 2 & Liquid & Dark black & 8.2 \\
\hline $\mathbf{3}$ & Soli 1 & solid & Black & 5.7 \\
\hline $\mathbf{4}$ & Soil 2 & solid & brown & 4.6 \\
\hline
\end{tabular}

Table.2 Decolourization of Reactive black GDN by bacterial isolates ISO1 to ISO8 (Dye 100 $\mathrm{mg} \mathrm{l}^{-1}$ )

\begin{tabular}{|c|c|}
\hline Bacterial isolates & Decolourization (\%) Reactive Black GDN \\
\hline ISO1 & $26 \%$ \\
\hline ISO2 & $15 \%$ \\
\hline ISO3 & $40 \%$ \\
\hline ISO4 & $94 \%$ \\
\hline ISO5 & $40 \%$ \\
\hline ISO6 & $90 \%$ \\
\hline ISO7 & $73 \%$ \\
\hline ISO8 & $12 \%$ \\
\hline
\end{tabular}

Table.3 Microscopic observation of isolates collected from soil and effluent the Sachin GIDC, Surat

\begin{tabular}{|c|c|c|c|}
\hline No. of Isolates & Gram's reaction & Colour of cells & Motility \\
\hline ISO-1 & Gram Negative & Pink & Non motile \\
\hline ISO-2 & Gram Negative & Pink & Motile \\
\hline ISO-3 & Gram Positive & Purple & Motile \\
\hline ISO-4 & Gram Negative & Pink & Motile \\
\hline ISO-5 & Gram Negative & Pink & Motile \\
\hline ISO-6 & Gram Negative & Pink & Motile \\
\hline ISO-7 & Gram Negative & Pink & Motile \\
\hline ISO-8 & Gram Negative & Pink & Motile \\
\hline
\end{tabular}

Table.4 Colony characteristics of isolates

\begin{tabular}{|c|c|c|c|c|c|c|c|c|}
\hline Isolates & Size & Shape & Margin & Elevation & surface & Consistency & Opacity & Pigmentation \\
\hline ISO - 1 & L & Round & Entire & Convex & Smooth & B & OP & NP \\
\hline ISO - 2 & S & Round & Even & Low convex & Smooth & Gummy & OP & DW \\
\hline ISO - 3 & L & Irregular & Irregular & Flat & Rough & Dry & OP & NP \\
\hline ISO - 4 & L & Round & Entire & Convex & Smooth & B & TP & NP \\
\hline ISO - 5 & L & Round & Even & Flat & Smooth & B & TL & GB \\
\hline ISO - 6 & S & Round & Entire & Flat & Smooth & B & TL & LY \\
\hline ISO - 7 & S & Irregular & Uneven & Convex & Rough & Dry & OP & NP \\
\hline ISO - 8 & S & Irregular & Uneven & Convex & Rough & Dry & OP & NP \\
\hline
\end{tabular}

NOTES: $\mathrm{S}=$ Small, $\mathrm{L}=$ Large, $\mathrm{B}=$ Buterious, $\mathrm{OP}=$ Opaque, $\mathrm{TP}=$ Transparent, $\mathrm{TL}=$ Translucent, $\mathrm{NP}=\mathrm{No}$ pigment, DW $=$ Dirty White, $\mathrm{GB}=$ Greenish Blue, $\mathrm{LY}=$ Light Yellow. 
Table.5 Biochemical Characterization of selected bacterial isolates from effluent and soil

\begin{tabular}{|c|c|c|c|c|c|c|c|c|}
\hline $\begin{array}{c}\text { Biochemical } \\
\text { Tests }\end{array}$ & ISO - & ISO - & ISO - & ISO - & ISO - & ISO - & ISO - & ISO - 8 \\
\hline Oxidase & $\mathbf{N}$ & $\mathbf{2}$ & $\mathbf{3}$ & $\mathbf{4}$ & $\mathbf{5}$ & $\mathbf{6}$ & $\mathbf{7}$ & \\
\hline Catalase & $\mathbf{P}$ & $\mathbf{N}$ & $\mathbf{N}$ & $\mathbf{P}$ & $\mathbf{P}$ & $\mathbf{N}$ & $\mathbf{P}$ & $\mathbf{P}$ \\
\hline Indole & $\mathbf{N}$ & $\mathbf{N}$ & $\mathbf{N}$ & $\mathbf{P}$ & $\mathbf{P}$ & $\mathbf{P}$ & $\mathbf{P}$ & $\mathbf{P}$ \\
\hline M-R & $\mathbf{N}$ & $\mathbf{N}$ & $\mathbf{N}$ & $\mathbf{N}$ & $\mathbf{N}$ & $\mathbf{N}$ & $\mathbf{N}$ & $\mathbf{N}$ \\
\hline V-P & $\mathbf{N}$ & $\mathbf{P}$ & $\mathbf{P}$ & $\mathbf{N}$ & $\mathbf{P}$ & $\mathbf{P}$ & $\mathbf{N}$ & $\mathbf{N}$ \\
\hline Citrate & $\mathbf{P}$ & $\mathbf{P}$ & $\mathbf{P}$ & $\mathbf{P}$ & $\mathbf{P}$ & $\mathbf{N}$ & $\mathbf{P}$ & $\mathbf{P}$ \\
\hline Urease & $\mathbf{P}$ & $\mathbf{N}$ & $\mathbf{N}$ & $\mathbf{N}$ & $\mathbf{P}$ & $\mathbf{P}$ & $\mathbf{N}$ & $\mathbf{N}$ \\
\hline Starch & $\mathbf{N}$ & $\mathbf{P}$ & $\mathbf{P}$ & $\mathbf{N}$ & $\mathbf{N}$ & $\mathbf{N}$ & $\mathbf{N}$ & $\mathbf{N}$ \\
\hline H$_{2}$ S Production & $\mathbf{N}$ & $\mathbf{P}$ & $\mathbf{N}$ & $\mathbf{N}$ & $\mathbf{N}$ & $\mathbf{P}$ & $\mathbf{N}$ & $\mathbf{N}$ \\
\hline TSI & $\mathbf{P}$ & $\mathbf{N}$ & $\mathbf{N}$ & $\mathbf{N}$ & $\mathbf{P}$ & $\mathbf{P}$ & $\mathbf{N}$ & $\mathbf{N}$ \\
\hline Gelatine & $\mathbf{N}$ & $\mathbf{P}$ & $\mathbf{N}$ & $\mathbf{N}$ & $\mathbf{P}$ & $\mathbf{N}$ & $\mathbf{N}$ & $\mathbf{N}$ \\
\hline Glucose & $\mathbf{P}$ & $\mathbf{P}$ & $\mathbf{P}$ & $\mathbf{P}$ & $\mathbf{P}$ & $\mathbf{P}$ & $\mathbf{P}$ & $\mathbf{P}$ \\
\hline Sucrose & $\mathbf{P}$ & $\mathbf{P}$ & $\mathbf{P}$ & $\mathbf{P}$ & $\mathbf{P}$ & $\mathbf{P}$ & $\mathbf{P}$ & $\mathbf{P}$ \\
\hline
\end{tabular}

Notes : $\mathrm{P}=$ Positive test, $\mathrm{N}=$ Negative test, $\mathrm{MR}=$ Methyl red test, $\mathrm{VP}=$ Voges Proskauer, $\mathrm{TSI}=$ Triple sugar iron test.

Fig.1 a) treatment with ISO5 and b) treatment with ISO4, Samples collected before and after treatment of textile effluent (Sachin GIDC, Surat, Gujarat.)

a)

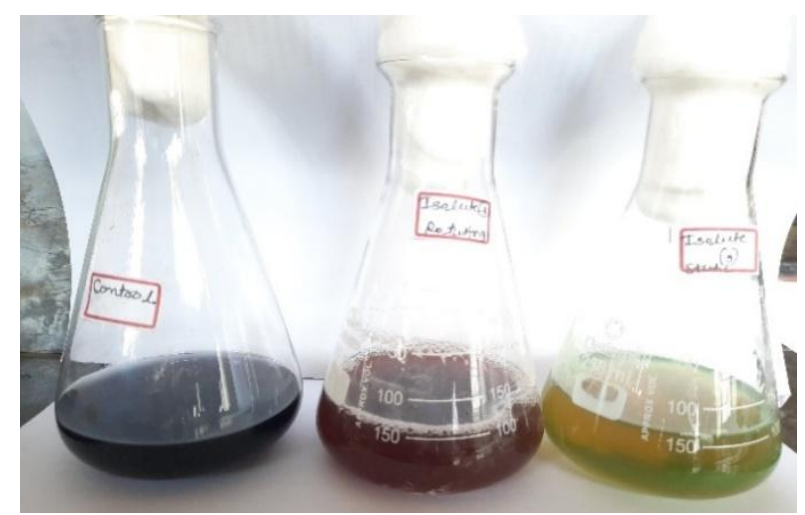

b)

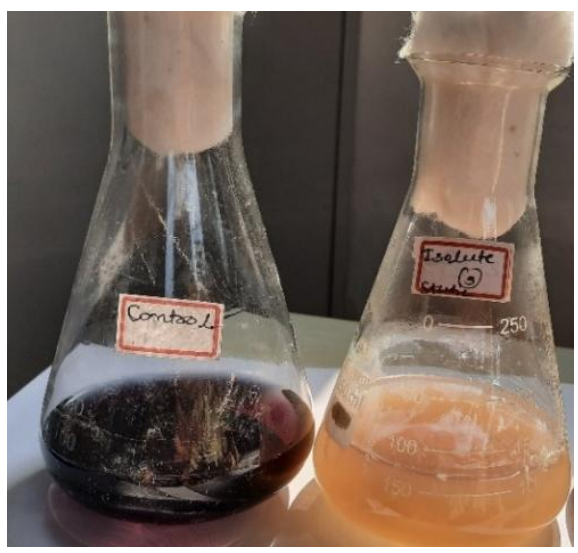


Fig.2 Microscopic Gram staining observation of isolates collected from soil and effluent the Sachin GIDC, Surat. a) Gram Negative and b) gram positive

a)

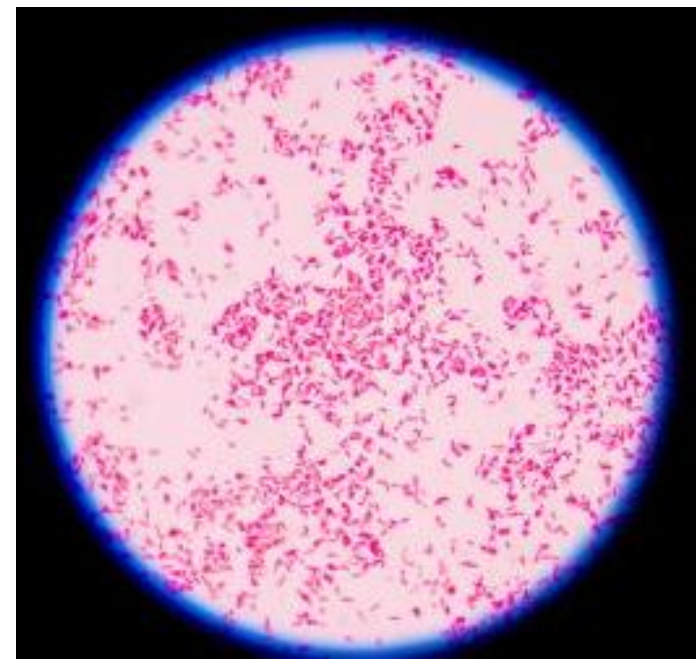

b)

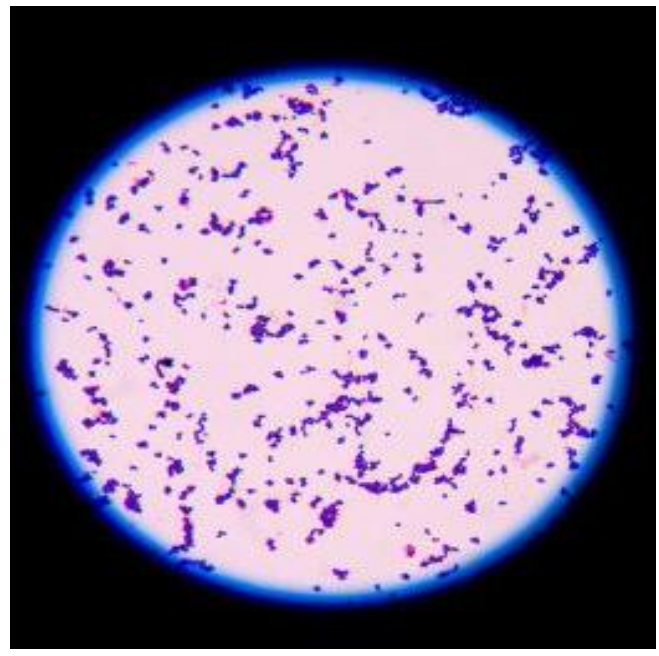

Fig.3 Isolates on Nutrient Agar Plate
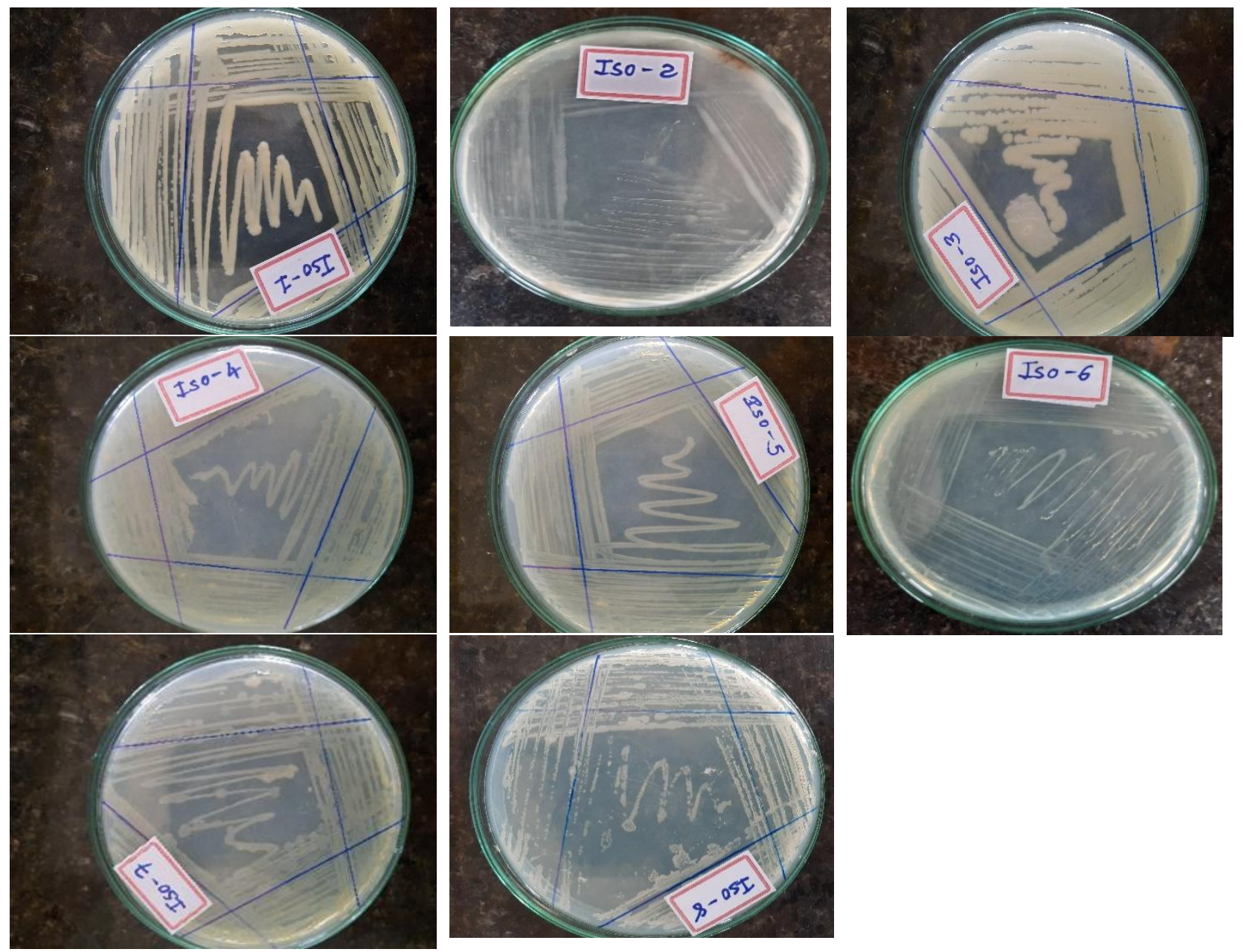
Fig.4 Results of various Biochemical test

a)+ve test on cimmon

Citrate

b) control

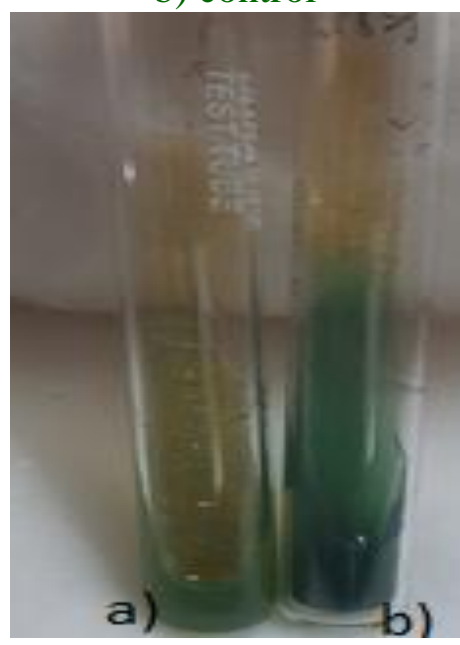

a)+ve glucose fermenter test

b) control

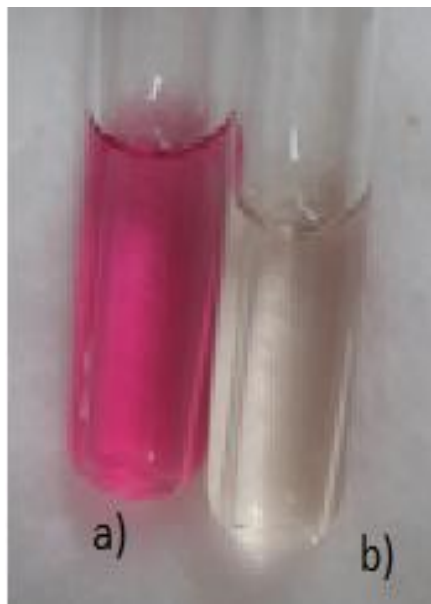

a)+ve test on TSI Slant

b)control

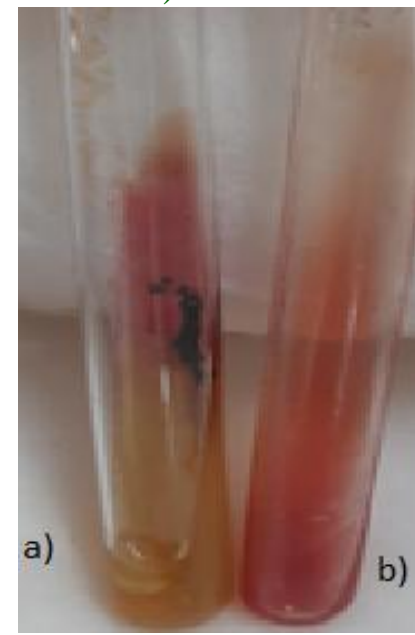

Fig.5 Degradation of Reactive black GDN at $\mathrm{pH} 4$ by various types of Isolates

\section{Degradation at $\mathrm{pH} 4$}

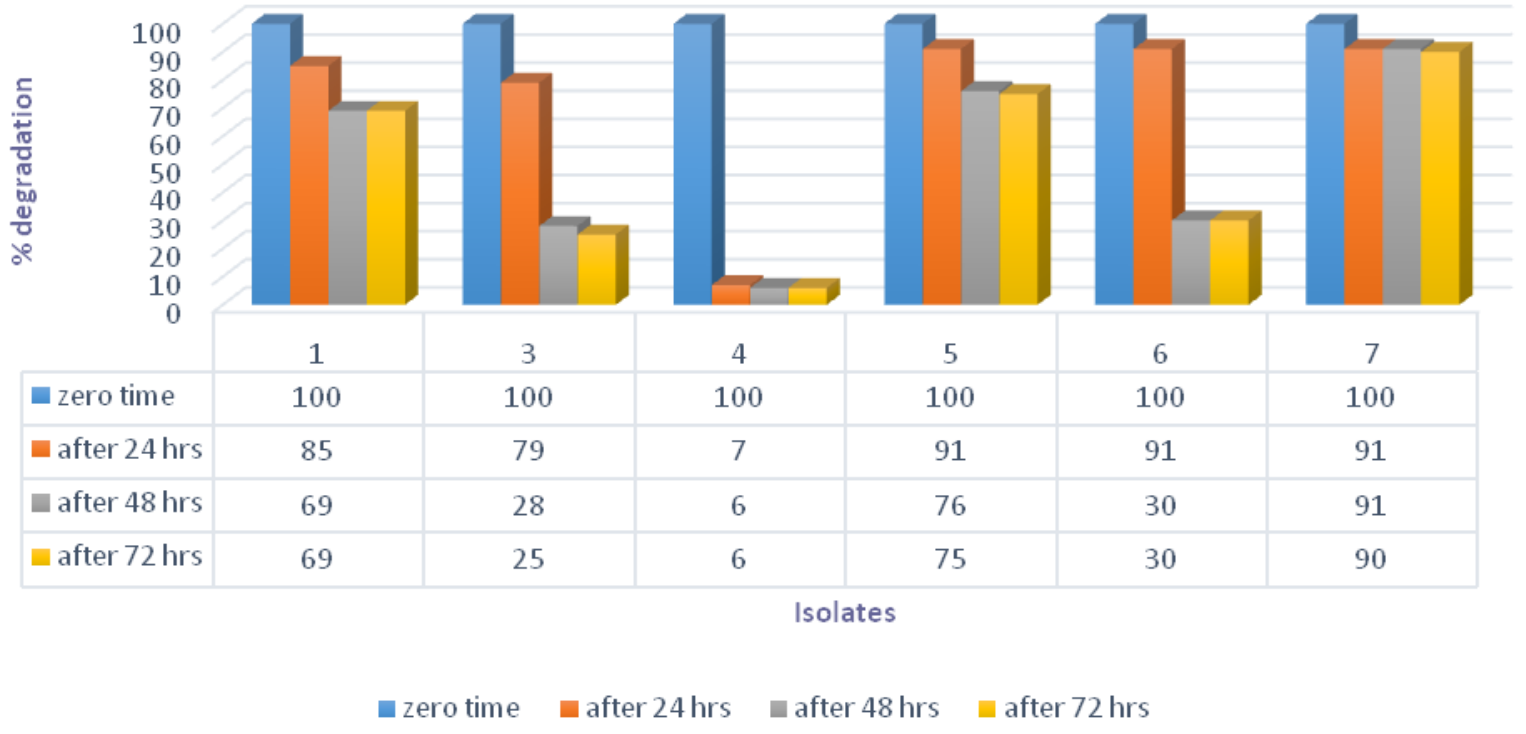


Fig.6 Degradation of Reactive black GDN at $\mathrm{pH} 8$ by various types of Isolates

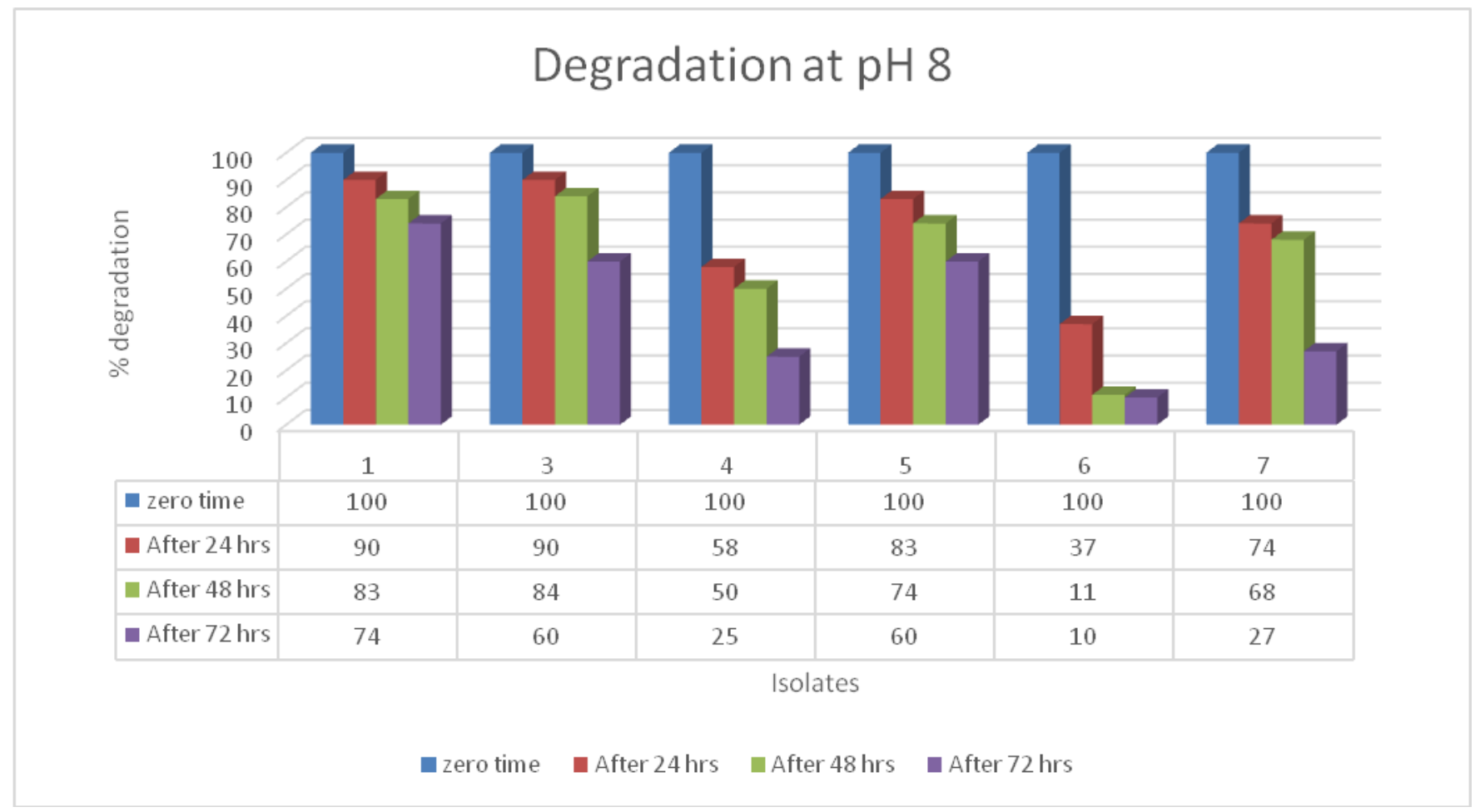

Fig.7 Degradation of Reactive black GDN varied with incubation time at $\mathrm{pH} 7$ by various types of Isolates

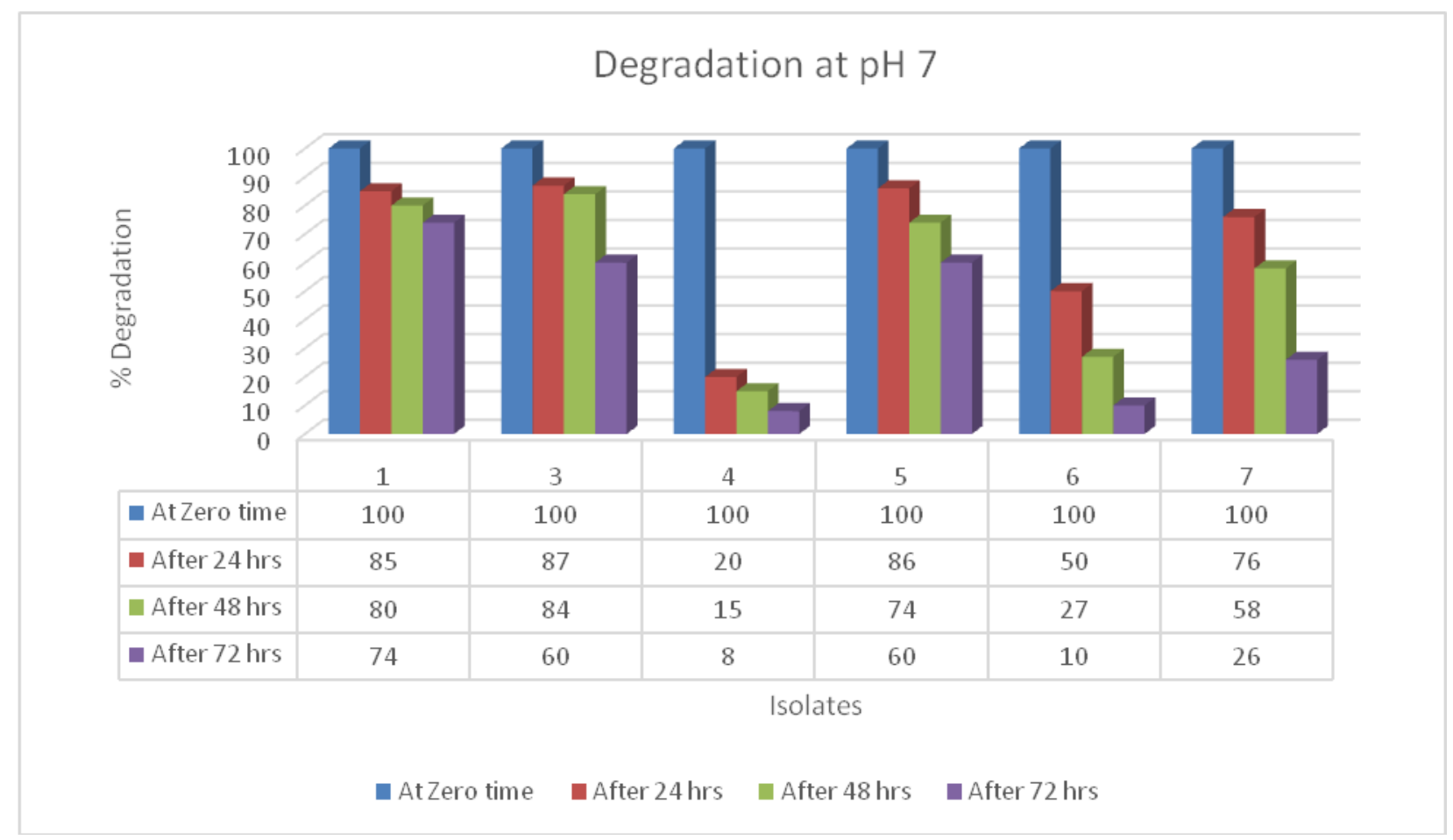




\section{Biochemical Tests}

Bacterial isolates were considered for their characterization, based on Gram's reaction, cell morphology, colony characteristics, growth patterns in nutrient broth and biochemical tests. Table 3 and Table 4 show results of various characters studied.ISO1, ISO1, ISO2, ISO3, ISO4, ISO5, ISO6, ISO7, and ISO8 produced acid present in TSI which is evidenced by conversion of slants from red to yellow. The result showed that many of them occurred commonly in such environment.

\section{Effect of pH}

The $\mathrm{pH}$ tolerance is an important consideration for industrial applications because processes using reactive azo dyes are usually performed under alkaline conditions. (Aksu and Tezer, 2005). The experiment was performed in $250 \mathrm{ml}$ Erlenmeyer flasks containing $100 \mathrm{ml}$ nutrient broth medium with $100 \mathrm{mg} / \mathrm{l}$ dye. It was observed that the percentage of dye decolourisation varied with change in $\mathrm{pH}$ of the medium (Graph.5, 6 and 7).

Although decolourisation rate peaked around $\mathrm{pH} 8$ at $18 \mathrm{hrs}$, the organism decolorized more than $96 \%$ of the dye by incubation up to $24 \mathrm{hrs}$ on wide range of $\mathrm{pH}$ (4-7-8). However, ISO1, ISO3, ISO6 and ISO7 organism showed very poor decolourisation at the $\mathrm{pH}$ 4.ISO4 shows 94\% degradation at $\mathrm{pH} 4$ respectively (Graph.5). ISO7 and ISO8 shows No growth was observed at $\mathrm{pH} 4$.

These observations indicated that the organism can treat basic dyeing waste water at normal operational $\mathrm{pH}$ and decrease the cost of acidification (Ayed et al., 2009). Graph.5,6 and 7 depicted the effect of various $\mathrm{pH}$ on decolourisation process under steady condition. Under steady condition ISO6 showed reduced decolourisation of
$87 \%$ and $48 \%$ at $\mathrm{pH} 8$, respectively; while under steady the organism showed increased decolourisation of $100 \%$ and $93 \%$ at $\mathrm{pH} 8$.

At lower $\mathrm{pH}$ values, the $\mathrm{H}+$ ions compete effectively with dye cations, causing a decrease in colour removal efficiency.

Furthermore, at high $\mathrm{pH}$, the surface of biomass gets negatively charged, which enhance the positively charged dye cations through electrostatic force of attraction.

\section{Effect of incubation time}

The experiment was performed in $250 \mathrm{ml}$ Erlenmeyer flasks containing $100 \mathrm{ml}$ nutrient broth medium with $100 \mathrm{mg} / \mathrm{l}$ dye. It was observed that the percentage of dye decolourisation varied with incubation time (Graph.7).ISO4 Shows 92\% degradation in $24 \mathrm{hrs}$ and ISO6 and ISO7 shows maximum degradation after $72 \mathrm{hrs}$ at $\mathrm{pH} 7$.

Two bacterial isolates,ISO4 shows maximum degradation at $\mathrm{pH} 4$ at $37^{\circ} \mathrm{cin}$ $24 \mathrm{hrs}$ and ISO6 shows maximum degradation at $\mathrm{pH} 8$ at $37^{\circ} \mathrm{c}$ in $48 \mathrm{hrs}$ under steady condition bacterial isolates having the best capability to decolorize reactive textile dyes were screened and their biochemical characteristics.

The decolourisation of Reactive Black GDN by the bacterial isolates is due to biodegradation and is dependent on various physico-chemical parameters.

Degradation and decolorizing activity against Reactive black GDN dye suggests that the bacterial isolates in this study have potential practical application in the biotransformation of various dye effluents. Currently, research is going on to characterize the enzymes, especially laccase, peroxidase and azoreductase, of these bacterial isolates. 


\section{References}

Acuner, E., Dilek, F.B., 2006. Treatment of tectilon yellow $2 \mathrm{G}$ by Chlorella vulgaris. Process Biochem. 39 (5), 623-631.

Aksu, Z., 2005. Application of biosorption for the removal of organic pollutants: a review. Process Biochem. 40 (3), 9971026.

Aksu, Z., Donmez, G. 2005. Combined effects of molasses sucrose and reactive dye on the growth and dye bioaccumulation properties of Candida tropicalis. Process Biochemistry. 40: 2443-2454.

Axelsson, J., Nilsson, U., Terrazas, E., Alvarez Aliaga, T., Welander, U.,2006.Decolourization of the textile dyes Reactive Red 2 and Reactive Blue 4 using Bjerkandera sp. Strain BOL 13 in a continuous rotating biological contactor reactor. Enzym. Microb. Technol. 39 (1),32-37.

Ayed, L., Chaieg, K., Cheref, A., Bakhrouf, A., 2009. Biodegradation of triphenylmethane dye malachite green by Sphingomonas paucimobilis. World J Microbiol Biotechnol. 25: 705-711

Ayed, L., Khelifi, E., Jannet, H.B., Miladi, H., Cheref, A., Achour, S., Bakhrouf, A., 2010. Response surface methodology for decolourisation of azo dye Methyl Orange by bacterial consortium: produced enzymes and metabolites characterization. Chem. Eng. J. 165 (1),200-208.

Azad, A.K., Sawa, Y., Ishikawa, T., Shibata, H., 2009. Heterologous expression of tulip petal plasma membrane aquaporins in Pichia pastoris for water channel analysis. Appl. Environ. Microbiol. 75 (9),2792-2797.

Bartholomew J w, Mittwer t.,1952. The Gram stain. Bacteriol Rev. Mar;16(1):1-29.

Celia, M.P., Suruthi, S., 2016. Textile dye degradation using bacterial strains isolated from textile mill effluent. Int.
J. Appl. Res. 2 (3), 337-341

Chen, K.C., Wu, J.Y., Liou, D.J., Hwang, S.C.J., 2003. Decolourization of the textile dyes by newly isolated bacterial strains. J. Biotechnol. 101 (1),57-68.

Chindah, A.C., Braide, S., Sibeudu, O.C., 2004. Distribution of hydrocarbons and heavy metals in sediment and a crustacean (shrimps - Penaeus notialis) from the Bonny/New Calabar River Estuary, Niger Delta. Afr. J. Environ. Assess. Manag. 9,1-17.

Daneshvar, N., Khataee, A.R., Rasoulifard, M.H., Pourhassan, M., 2005. Biodegradation of dye solution containing Malachite Green: optimization of effective parameters using Taguchi method. J. Hazard Mater. 143 (1-2), 214-219.

Farhana, K., Syduzzaman, M., Munir, M.S., 2015. Present status of workers in ready-made garments industries in Bangladesh. Eur. Sci. J. 11 (7).

Gupta, V. K., Ali, I., Suhas, Mohan, D., 2003. Equilibrium uptake and sorption dynamics for the removal of a basic dye (basic red) using low-cost adsorbents. J. Colloid Interface Sci. 265 (2),257-264.

Kurade, M.B., Waghmode, T. R., Patil, S. M., Jeon, B.H., Govindwar, S. P., 2017. Monitoring the gradual biodegradation of dyes in a simulated textile effluent and development of a novel triple layered fixed bed reactor using a bacterium-yeast consortium. Chem. Eng. J. 307, 1026-1036.

Lin, S.H., Peng, C.F., 1994. Treatment of textile waste water by electrochemical method. Water Res. 28 (2),277-282.

Mishra, A., Malik, A., 2014. Novel fungal consortium for bioremediation of metals and dyes from mixed waste stream. Bioresour. Technol. 171,217226.

Mohan, S. V., Rao, N. C., Srinivas, S., Prasad, K. K., Karthikeyan, J., 2008. Treatment of simulated Reactive Yellow 22 (azo) dye effluents using 
Spirogyra species. Waste Manag. (New York, N.Y.) 22 (6) (2008) 575582. Mona, E.M., Yusef, H., Decolourization of fast red by Bacillus subtilis H M. J. Appl. Sci. Res. 4 (3),262-269.

Pandey, A., Singh, P., Iyengar, L., 2007. Bacterial decolourisation and degradation of azo dyes. Int. Biodeterior. Biodegrad. 59 (2), 73-84

Rauf, M.A., Salman Ashraf, S., 2012. Survey of recent trends in biochemically assisted degradation of dyes. Chem. Eng. J. 209, 520-530.

Rovira, J., Domingo, J.L., 2019. Human health risks due to exposure to inorganic and organic chemicals from textiles: a review. Environ. Res. 168,62-69.

Sarioglu, M., Bali, U., Bisgin, T., 2007. The removal of C.I. Basic Red 46 in a mixed methanogenic anaerobic culture. Dyes Pigments 74 (1),223229.

Shah, M. P., Patel, K. A., Nair, S. S., Darji, A. M., 2013. Molecular characterization and optimization of Azo dye degrading Bacillus subtillis ETL. A Mol. Cell Biol. 1 (1),2.

Shen, N., Huo, Y. C., Chen, J. J., Zhang, F., Zheng, H., Zeng, R. J., 2015. Decolourization by Caldicellulosiruptor saccharolyticus with dissolved hydrogen under extreme thermophilic conditions. Chem. Eng. J. 262, 847-853.

Shuchismita, D., Ashraful, I., 2015. A review on textile wastewater characterization in Bangladesh. Resour. Environ. 5,1544.

Staley, J. R., Boone, A. R., Brenner, D. J., Vos, P. D., Garrity, G. M., Good fellow, M., Krieg, N. R., Rainey, F.
A., Schleifer, K. H., 2001. Bergey's Manual ${ }^{\circledR}$ of Systematic Bacteriology, second ed. Springer.

Stiborova, M., Dracinska, H., Martinek, V., Svaskova, D., Hodek, P., Milichovsky, J., Hejdukova, Z., Brotanek, J., Schmeiser, H. H., Frei, E., 2013. Induced expression of cytochrome $\mathrm{P} 450$ 1A and NAD(P) Quinone oxidoreductase determined at mRNA, protein, and enzyme activity levels in rats exposed to the carcinogenic azo dye 1- phenylazo-2-naphthol (Sudan I). Chem. Res. Toxicol. 26 (2),290299.

Sultana, M., Shahidul Islam, M., Saha, R., Mansur, M., 2009. Impact of the effluents of textile dyeing industries on the surface water quality inside D.N.D Embankment, Narayanganj. Bangladesh J. Sci. Ind. Res. 44. Tamura, K., Peterson, D., Peterson, N., Stecher, G., Nei, M., Kumar, S., 2011. MEGA5: molecular evolutionary genetics analysis using maximum likelihood, evolutionary distance, and maximum parsimony methods. Mol. Biol. Evol. 28 (10),2731-2739.

Veena, S., Rao, B., Venkata, K., 2019. Biodegradation of Textile Azo Dyes. Nano science and Biotechnology for Environmental Applications. Springer International Publishing, Cham, pp.,115-139.

Wanyonyi, W.C., Onyari, J.M., Shiundu, P.M., $\quad$ Mulaa, F.J., 2017. Biodegradation and detoxification of malachite green dye using novel enzymes from Bacillus cereus strain KM201428: kinetic and metabolite analysis. Energy Proc. 119,38-51.

\section{How to cite this article:}

Palkesh D. Gandhi and Sumaiya A. Shaikh. 2021. Biodegradation of Textile Dye Reactive Black GDN by Free Cells Isolated from Soil and Textile Effluents. Int.J.Curr.Microbiol.App.Sci. 10(04): 103-115. doi: https://doi.org/10.20546/ijcmas.2021.1004.010 